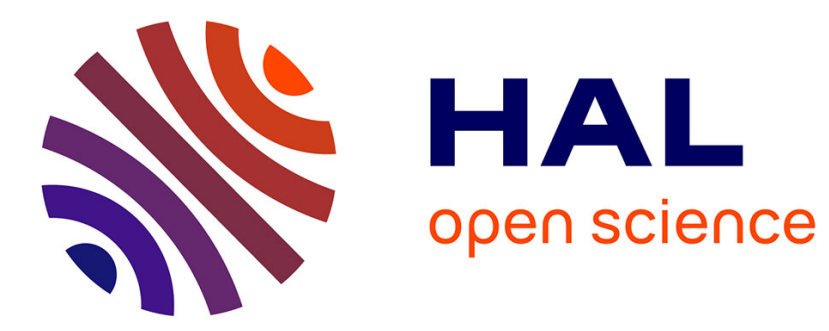

\title{
Knowledge accumulation within an organization
}

Ngo van Long, Antoine Soubeyran, Raphael Soubeyran

\section{To cite this version:}

Ngo van Long, Antoine Soubeyran, Raphael Soubeyran. Knowledge accumulation within an organization. [University works] Inconnu. 2012, 30 p. hal-02118107

\section{HAL Id: hal-02118107 https://hal.science/hal-02118107}

Submitted on 2 May 2019

HAL is a multi-disciplinary open access archive for the deposit and dissemination of scientific research documents, whether they are published or not. The documents may come from teaching and research institutions in France or abroad, or from public or private research centers.
L'archive ouverte pluridisciplinaire HAL, est destinée au dépôt et à la diffusion de documents scientifiques de niveau recherche, publiés ou non, émanant des établissements d'enseignement et de recherche français ou étrangers, des laboratoires publics ou privés. 


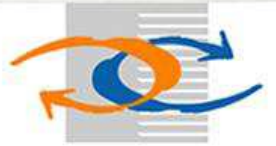

\section{A M E T A}

Laboratoire Montpelliérain d'Economie Théorique et Appliquée

U M R

Unité Mixte de Recherche

« Knowledge Accumulation

within an Organization »

Ngo Van LONG

Antoine SOUBEYRAN

Raphael SOUBEYRAN

DR $n^{\circ} 2012-03$

Unite de Formation et de Recherche d'Economie Avenue Raymond DUGRAND C.S. 79606

34960 MONTPELLIER Cedex 2

E-mail : lameta@lameta.univ-montp1.fr web : www.lameta.univ-montp1.fr 


\title{
Knowledge Accumulation within an Organization
}

\author{
Ngo Van Long* Antoine Soubeyran ${ }^{\dagger} \quad$ Raphael Soubeyran ${ }^{\ddagger}$
}

This version: January 2012

\begin{abstract}
We develop a simple model of task allocation for knowledge workers over their career within an organization. The human capital theory initiated by Becker $(1962,1964)$ has offered a rich analysis of an individual's life cycle investment in human capital. One of the main result of this literature states that human capital investments are undertaken at the early stage of the career because workers have then a longer period of time over which they can benefit from the return of their investments. In this paper, we consider a knowledge accumulation problem within an organization that cannot prevent the worker from quitting and using the knowledge outside the organization. In the first best situation, we show a similar result as in the human capital theory, i.e. the share of time allocated to knowledge creation tasks decreases over time. We then ask how this pattern is affected when the knowledge worker can leave the organization and benefit from this knowledge outside the organization. In this case, we obtain the novel result that the time path of the fraction of working time allocated to knowledge creation tasks is non-monotone. This fraction is highest at the early career stage, falls gradually, then rises again, before falling finally toward zero. We also show that an increase in the firm-specificity of knowledge can increase or decrease the life-time income of the knowledge worker.
\end{abstract}

JEL codes: J24, C61, D23, J41, L00

\footnotetext{
*Department of Economics, McGill University, Montreal H3A 2T7, Canada. Email: ngo.long@mcgill.ca.

† GREQAM, Université Aix-Marseille II. Email: antoine.soubeyran@univmed.fr

${ }^{\ddagger}$ INRA-LAMETA, Montpellier, France. Email: soubeyra@supagro.inra.fr
} 


\section{Introduction}

The wealth of modern economies depends increasingly on knowledge-based activities and nowadays knowledge workers represent a large share of the workforce. ${ }^{1,2}$ Peter Drucker (1995), credited with coining the term knowledge worker, defines these individuals as "high level employees who apply theoretical and analytical knowledge, acquired through formal education, to develop new products or services." Examples of knowledge workers include professionals, scientists, educators, information system designers, and academics. These workers cannot be managed as usual subordinates because knowledge workers are often motivated by challenging tasks and interested in their work. ${ }^{3}$

One of the main issues in leading knowledge workers is how to retain them in the firm, as monetary incentives alone are often not sufficient. ${ }^{4}$ The nature of the tasks given to knowledge workers are an important incentive to retain them in the firm (Prince, 2011). Companies often propose new tasks to their knowledge workers, and academic departments of research-oriented universities assign teaching loads and administrative responsibilities (that constraint research time) that vary along the career path. ${ }^{5}$

The human capital theory initiated by Becker $(1962,1964)$ and Mincer $(1958,1962)$ has offered a rich analysis of an individual's life cycle investment in human capital. One of the main result of this literature states that human capital investments are undertaken at the early stage of the career because workers have then a longer period of time over which they can benefit from the return of their investments. Becker's focus on the investment demand side has been complemented by supply-side considerations offered by Ben-Porath (1967), who assumed that an individual must allocate a fraction of his human capital as an input, to be combined with purchased inputs, in his investment in human capital. Ben-Porath showed that this fraction is changing over time, and generally it becomes smaller and smaller as the individual approaches the retirement age. ${ }^{6}$ Both the Becker mechanism and the Ben-Porath

\footnotetext{
${ }^{1}$ According to the OECD (1996), more than 50 per cent of Gross Domestic Product in the major OECD economies is knowledge-based.

${ }^{2}$ For 2004, US occupational surveys suggest that jobs that might be categorised as knowledge economy account for around 27 per cent of total employment. Knowledge workers account for between $40 \%$ and $50 \%$ of the workforce in Northern European countries and between 20\% to $30 \%$ in Southern European countries. (Source: ILO.)

${ }^{3}$ See the report on the interview with Robert Austin, Associate Professor at Harvard Business School, in Science's Next Wave, 26 April 2002. Drucker argues that knowledge workers have to be led rather than to be managed.

${ }^{4}$ Alberto Savoia, a former Google engineer, "left Google in 2002 to start a software company [...] He left 240,000 unvested options on the table, worth $\$ 120$ million had he stayed".(Forbes.com, 2007).

${ }^{5}$ For instance, Google's engineers can work $20 \%$ of their time on independant projects.

${ }^{6}$ Ben-Porath made the distinction between observed earnings and earnings net of all investment costs:
} 
mechanism predict that for any individual the investment in human capital declines over time. In this paper, we consider a different mechanism that, unlike the other two previous mechanisms, is capable of producing a non-monotone path of investment in human capital. The driver behind our result is the role of the employer, who actively offers the knowledge workers time-varying financial and non-financial incentives to stay with the firms. In the first best situation, where the employer and the knowledge worker can sign binding contracts, we show a result similar to the standard human capital theory, i.e., the share of time allocated to a knowledge creation task decreases over time. In the second-best situation, where the knowledge worker can leave the organization and use the accumulated knowledge to earn income outside the organization, we show that the time path of investment in human capital can be non-monotone.

More precisely, we study the problem of an organization which seeks the optimal allocation of the working time of a knowledge worker between two types of tasks, knowledgecreation tasks and routine tasks, along the career of the knowledge worker as an instrument to retain her in the organization. The knowledge creation tasks add to the employee's knowledge stock, which itself generates profits for the firm, and at the same time increase the employee's income prospect in outside options. This latter aspect provides incentives for her to quit the firm. How much her knowledge stock is useful in outside option employment depends on the extent to which the knowledge is firm-specific. The routine tasks contribute to the immediate profits for the firm but do not add to the employee's knowledge stock. The firm therefore faces both a static tradeoff and a dynamic tradeoff in deciding on the fraction of time to be allocated to the knowledge creation tasks. We assume that the employer offers a contract that stipulates the fraction of working time the employee has to spend in the routine tasks. At any point of time the employee has the option to leave the firm. We investigate the nature of the terms of employment that would maximize the firm's payoff, subject to the constraint that sufficient incentives are given to ensure that the employee would not gain by quitting.

One of our novel results is that the allocation of working time between the knowledge creation tasks and the routine tasks evolves non-monotonically. At the beginning of her career, the worker is asked to spend a large share of her time in the knowledge creation tasks, but gradually she is asked to allocate an increasing share of time to the routine tasks. Around the middle of her career, this trend reverses and the employer allows the knowledge worker to devote more and more time to the knowledge creation tasks. Toward the end the former are always higher, change slower, and peaks at an earlier date than the latter. 
of her career, the trend reverses again and the knowledge worker is asked to perform more and more routine tasks. We also show that the higher the degree of firm-specificity of the stock of knowlege, the greater will be the amount of knowledge accumulated over the whole horizon. Somewhat surprisingly, an increase in the firm-specificity of knowledge can increase or decrease the life-time income of the knowledge worker.

An example that seems to fit our model is academic contracts. Academics perform research tasks but also teaching and administrative tasks. Research is a cumulative investment for the academic and the university department, and it is valuable outside the employee's current organization, whereas teaching and administrative tasks generate value for the university but are less valuable for the academic outside the university. The chairman of the department normally gives reduced teaching loads (course reduction) to young researchers, but such reduction falls as the years go by. Later in the career, academics can leave temporally for sabbatical periods, which allow them to spend more time on their research.

As already mentionned, our paper contributes to the literature on the accumulation of human capital within an organizational context. Other papers have considered the human capital accumulation problem within an organization. Smid and Volkerink (1999) extend the analysis of specific schooling by Hashimoto (1981) by introducing non-specific or general schooling within a two-period framework. In the first period, the employer and the employee not only have to choose the level of investment in human capital and the division of costs and benefits, but also have to decide on the specificity of the training. In the second period, (private) information on the productivity of schooling becomes available, and the employee may decide to quit, or the employer may dismiss the employee. They analyze the consequences of subsidies or taxes on schooling. The degree of specificity of training is an also important feature of our paper. However, we consider the specificity of knowledge as an exogenous parameter and analyse its influence on knowledge accumulation and on the life-time earning of the knowledge worker.

Our paper contributes to the literature on the hold-up problem by exploring a tradeoff that has not been analysed previously. On the one hand, by letting the knowledge worker accumulate knowledge early, the employer obtains large returns on this investment as long as the worker stays with the firm, but the incentives for the worker to quit becomes stronger over time until she approaches her retirement age. On the other hand, letting the knowledge worker accumulate knowledge later, the employer obtains lower returns because the remaining horizon is shorter, but the incentives for the worker to quit become weaker. Hvide and Kristiansen (2011) also deal with the management of knowledge workers. They 
study how firm-specific complementary assets and intellectual property rights affect the management of knowledge workers. They focus on the trade-off between moral hazard and hold-up.

The hold-up problem is a crucial factor in the determination of the evolution of a bilateral relationship when agents make, ex ante, sunk and specific investments which will increase, ex post, the surplus of the relationship. Then, being unable, ex ante, to secure a share of the surplus in relation to the amount of their sunk investments, later agents will have to negotiate the division of the surplus, taking account that their bargaining power will have changed. ${ }^{7}$ The hold-up problem emerges in many bilateral exchanges, such as (i) workers and firms invest in firm-specific assets whose returns are shared through subsequent wage negotiation, or (ii) manufacturers and suppliers customize their equipment and production processes to their partners, (iii) team production, (iv) reallocation/dissolution of partnership assets, (v) political lobbying, and so on. Without special protections, the hold-up problem will lead parties to under-invest in specific assets. ${ }^{8}$

Our model is related to dynamic models of hold-up. Guriev and Kvasov (2005) show that if contracts are allowed to extend beyond the breakup of relationship, then efficiency can be achieved by a sequence of constantly renegotiated fixed term contracts, or a perpetual contract that allows unilateral termination with advanced notice. In our model, after the breakup the employer is allowed only limited compensation, and therefore efficiency is not achieved. In Pitchford and Snyder (2004) the seller can make gradual investment installments, and the buyer has an incentive to pay after each installment, so the hold-up problem can be mitigated, if there is no known, finite end to the number of installments. In our model, there is a finite end to the installments because the time horizon is finite. Furthermore, installment payments are not possible because the employee cannot borrow, and does not have adequate income to post a bond during training.

Che and Sakovics (2004) consider the role of anticipated future investments in a joint project. Two partners make investments and negotiate to share the surplus with an infinite horizon. Players receive payments only when an agreement is reached or when the game

\footnotetext{
${ }^{7}$ This is "the fundamental transformation" (Williamson, 1979), the value of their specific investments being different "out of the relationship" than "within".

${ }^{8}$ Various remedies have been proposed as safeguards against holdup, ranging from vertical integration (Klein et al.,1978, Williamson,1979), property rights allocation (Grossman and Hart, 1986, Hart and Moore, 1990), contracting on renegotiation rights (Chung, 1991, Aghion et al., 1994), option contracts (Nöldeke and Schmidt, 1995, 1998), production contracts (Edlin and Reichelstein, 1996), relational contracts (Baker, Gibbons, and Murphy (2002)), financial rights allocation (Aghion and Bolton,1992, Dewatripont and Tirole, 1994, and Dewatripont et al. 2003) and hierarchical authority (Aghion and Tirole, 1997) to injecting market competition (MacLeod and Malcomson, 1993, Acemoglu and Shimer,1999, Felli and Roberts, 2000, and Che and Gale, 2003).
} 
ends. Their main result is that for sufficiently patient players, the hold-up problem may be alleviated because of the shadow of the future. Smirnov and Wait (2004) focus on the timing of investments in a bilateral relationship where (i) two players can invest only once, and (ii) trade occurs only once and only if both players have made a specific investment. Their paper shows that if the potential investment horizon is continually extended, players pass in alternation from a prisoners' dilemma to a coordination game. Our model is very different from Che and Sakovics (2004) and Smirnov and Wait (2004) as we study a situation where players get payments all along the game. Compte and Jehiel (2003) study the effect of outside option (the value of which changes over time, depending on the history of offers and concessions) on the equilibrium of a bargaining game. They consider a complete information game that has two features. First, at any point of time, each party has the option to terminate the game (in contrast to our model, where only one party, namely the employee, has this option). Second, in case of termination, the payoffs are assumed to depend on the history of offers or concessions made in the bargaining process. They show that for a large class of such games, gradualism is a necessary feature. They also derive an upper bound on concessions.

Finally, even though our model's main focus is on how the time path of human capital accumulation is distorted because of incomplete contracts, it is also potentially useful for thinking about the "exploration and exploitation" relationship which has been discussed in the management literature where adaptive processes balance between the exploration of new possibilities and the exploitation of old certainties (Schumpeter 1934, Holland 1975). According to March (1991), "exploration includes things captured by terms such as search, variation, risk taking, experimentation, play, flexibility, discovery, innovation", while exploitation "includes such things as refinement, choice, production, efficiency, selection, implementation, execution". As noted by Ben Porath (1967), the pioneering work of Becker (1962, 1964) emphasized the demand side of human capital formation. Thus, Becker's focus is on the exploitation motive. Ben Porath (1967) emphasized the supply side, the investment costs. This reflects the exploration motive. In our paper we consider the two interrelated motives within an organization where the value of the outside option evolves endogenously. Our non-monotonicity result, which shows that the rate of change in knowledge comes in sudden bursts, may be viewed in the light of the theory of punctuated dynamics (Eldredge and Gould 1972), according to which evolution is not a gradual process. Periods of exploration where things change drastically are inserted between prolonged periods of exploitation where only minor changes take place. 


\section{Model and notations}

The time horizon $T$ represents the maximal career duration of the employee. Each period, the employee is endowed with a fixed working time (normalized to 1) to be split between time spent on the knowledge creation task, $k(t)$, and time spent on the usual task, $u(t)$. The time constraint of the employee is $k(t)+u(t)=1$. The employee's cumulated knowledge at $t$ is $K(t)=\int_{0}^{t} k(\tau) d \tau$.

Each period the employee obtains an ego-rent $I\left(K(t)\right.$ ) (with $I(0) \geq 0, I^{\prime}>0$ and $I^{\prime \prime} \leq 0$ ), which may be interpreted as her valuation of the prestige or pleasure derived from this stock. Inside the firm, the profit at time $t$ generated by the employee's cumulated knowledge is denoted $\pi(K(t))$ with $\pi(0) \geq 0, \pi^{\prime}>0$ and $\pi^{\prime \prime} \leq 0$.

We make a natural assumption concerning outside options: if the employee leaves the firm at time $t$, her expected future revenue (per period) is an increasing function of the stock of knowledge cumulated up to $t$. Her earning outside the firm will then be $\hat{\pi}(K(t))$, where we assume that $\hat{\pi}(K) \leq \pi(K)$, i.e. knowledge is more useful inside the firm than outside, and that $\hat{\pi}(0) \geq 0, \hat{\pi}^{\prime}>0$ and $\hat{\pi}^{\prime \prime} \leq 0$. Counting ego rent, she receives $s(K(t)) \equiv$ $\hat{\pi}(K(t))+I(K(t))$ each period of time $\tau>t$ outside the firm, using the knowledge cumulated up to $t$. After the employee quits, the firm obtains a constant value (normalized to 0 ) each remaining period of time.

As long as the employee remains with the firm, it earms the profit $\pi(K(t))$, and an additional amount $v(u(t))$ if the employee spends a fraction $u(t)$ of her time endowment on the routine tasks. Assume that for all $k \in[0,1], v(k) \geq 0, v^{\prime}(0)>0$ and $v^{\prime \prime}(k)<0$. The employee and the employer have the same discount rate $r \geq 0$.

At time $t=0$, the employer and the employee sign a contract. The contract specifies the fraction $k(\tau)$ of working time that must be devoted to the knowledge creation task, the remaining fraction being allocated to the routine task, $\tau \in[0, T]$, and a wage profile represented by $w(\tau)$ for $\tau \in[0, T]$. Thus, if the employee quits at time $t$, the cumulated payoff of the employee over the lifetime horizon is:

$$
V_{w}=\int_{0}^{t} e^{-r \tau}[I(K(\tau))+w(\tau)] d \tau+\int_{t}^{T} e^{-r \tau} s(K(t)) d \tau,
$$

and the cumulated payoff of the employer is

$$
V_{f}=\int_{0}^{t} e^{-r \tau}[\pi(K(t))+v(u(\tau))] d \tau-\int_{0}^{t} e^{-r \tau} w(\tau) d \tau
$$




\section{First best solution: the optimal length of a relation- ship}

For the sake of simplicity, we assume in the following that the discount rate is $r=0$. If the employee leaves the firm at time $t \leq T$, the joint surplus over the time horizon $T$ is given by

$$
J(t)=\int_{0}^{t}[I(K(\tau))+\pi(K(t))+v(u(\tau))] d \tau+\int_{t}^{T} s(K(t)) d \tau,
$$

where $k(t)+u(t)=1$. The opportunity cost of knowledge can be written as $v(u(t))=$ $v(1-k(t))$. The joint surplus optimization programme can then be written as

$$
\max _{0 \leq t \leq T, 0 \leq k(t) \leq 1}\left\{J(t)=\int_{0}^{t}[I(K(\tau))+\pi(K(t))+v(1-k(\tau))] d \tau+\int_{t}^{T} s(K(t)) d \tau\right\},
$$

where $0 \leq k(t) \leq 1$ and subject to

$$
\begin{gathered}
\dot{K}(t)=k(t), \\
K(0)=0 \text { (given). }
\end{gathered}
$$

Clearly, since $s(K) \leq I(K)+\pi(K)$ for all $K \geq 0$ and since $v(1-k) \geq 0$ for all feasible $k \in[0,1]$, the solution of the joint surplus maximization problem displays the plausible property that the two parties stay together until $T$. Another property concerns the fraction of time devoted to the knowledge creation task is decreasing over time, which is described in the following Proposition. ${ }^{9}$

Proposition 1 [First best allocation of time between tasks]: The optimal duration of the relationship is $t^{*}=T$ and the optimal (interior) splitting of working time is such that the share of time allocated to knowledge accumulation is decreasing whereas the share of time allocated to the routine task is increasing $(\dot{k}<0$ and $\dot{u}>0)$.

The joint surplus maximization requires that the share of working time allocated to the knowledge task decreases over time and that the share of time allocated to the routine task increases over time. In other words, the share of the routine task is gradually becoming dominant. Knowledge is accumulated mainly at the beginning of the career because the sooner the investment in the knowledge task, the larger the cumulative benefits. When the employee approaches the end of the horizon, the knowledge task becomes less attractive because there is less remaining time to exploit knowledge.

\footnotetext{
${ }^{9}$ All proofs are relegated to the Appendix.
} 
Let us illustrate this result with an example:

Example 1 [First best allocation of time between tasks]: Let us specify the functions as follows. $\pi(K)=A K$ with $A>0, \hat{\pi}(K)=\beta A K$ with $\beta \in(0,1), I(K)=D K$ with $D \geq 0$ and $v(u)=u-\frac{1}{2} u^{2}$. We also assume that $(A+D) T \leq 1$ which ensures the existence of an interior solution.

$$
k(t)=(A+D)(T-t) \text { and } u(t)=1-(A+D)(T-t)
$$

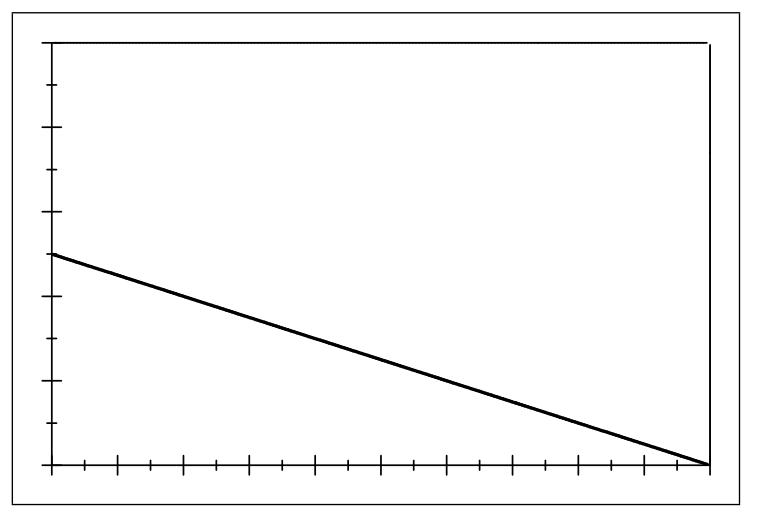

$(T=1, A+D=1 / 2)$

The first best solution is based on the assumption that both parties can commit to continuing their relationship until $T$. However, since the employee is accumulating knowledge, the value of her outside option is increasing over time, hence if the employee is free to quit at any time, she would have an incentive to quit unless the employer promises her sufficient reward for staying with the firm. This reward can come in two forms: a monetary reward, such as a time profile of salary that increases with seniority, or a prospect of accelerated increase in human capital in the future (which tilts the time path of her ego rent and that of her outside option toward the future). The next section investigates this issue.

\section{How to retain a knowledge worker using monetary rewards and non-monotone path of working time al- location}

We now consider the situation where the knowledge worker can quit at any time $t \in(0, T)$, taking with her the knowledge that she has acquired while being employed. The firm has two instruments to retain the worker: it prescribes a time path of allocation of working time between the knowledge creation task and the routine task, and it gives a monetary payment to the knowledge worker. We derive the properties of the optimal splitting of working time 
when the employer designs a scheme that prevents the knowledge worker from quitting the firm before the retirement age $T$. An interesting feature of our model is the optimal trade off (from the firm's vantage point) between these two instruments. The firm can maintain the first best time allocation scheme and keep the employee by promising a large sum of of terminal payment $S_{T}$, on the condition that the employee stays with it until $T$. But such a policy would be too expensive. The terminal payment can be much reduced if the employee has less valuable outside option, and this can be achieved if the firm reduces her path of accumulated human capital below the first best path. While this is intuitively plausible, what is not clear is whether it would be optimal for the firm to design a non-monotone path of working time allocation. Let us turn to this issue.

The knowledge worker receives a non-negative wage, $w(\tau)$, at time $\tau$. We assume that the firm cannot ask the worker to post a bond and it cannot ask her to pay any compensation once she has left. From time $t$, if the worker stays with the firm up to $T$ she enjoys a cumulated ego rent $\int_{t}^{T} I(K(\tau)) d \tau$ and a cumulated wage $\int_{t}^{T} w(\tau) d \tau$. If she chooses to leave the firm at time $t$, her payoff for the remaining working life is $V^{0}(t)=(T-t) s(K(t))$. It is important to notice that the value of her outside option, denoted by $V^{0}(t)$, evolves through time. The worker will not quit before the time horizon $T$ if the firm offers her a contract such that the following non-quitting constraint is satisfied:

$$
\int_{t}^{T} w(\tau) d \tau \geq(T-t) s(K(t))-\int_{t}^{T} I(K(\tau)) d \tau \text { for all } t \in[0, T] .
$$

The problem to be solved by the employer can then be written as follows:

$$
\max \int_{0}^{T}[\pi(K(\tau))+v(1-k(\tau))-w(\tau)] d \tau
$$

subject to

$$
\begin{gathered}
\dot{K}(t)=k(t), \\
K(0)=0 \text { (fixed), }
\end{gathered}
$$

and the non-quitting constraint (5).

Let us define $S_{T}$ as the total payment to the worker,

$$
S_{T}=\int_{0}^{T} w(\tau) d t
$$

By inspecting the objective function (6) and the constraint (5) and recalling the assumption that the employer can commit to honor the contract, we can see that the employer can 
pay the worker the lump sum $S_{T}$ at the end of the horizon, instead of spreading it over many periods. Does the possibility of introducing a non-monotone path of working time allocation help the firm to keep the worker, while trimming down the lump sum incentive component $S_{T}$ ? The following proposition and numerical example provide an answer to this question.

Proposition 2 [Second best allocation of time between tasks]: The second best program is very different from the first best program, and can be characterized as follows. If $k(t)>0$ over $[0, T)$,

(i) There exist at least one time interval $\left(t^{\prime}, t^{\prime \prime}\right)$ over which $k(t)$ is increasing, i.e. the employer promises a phase of acceleration of human capital accumulation in order to induce the agent to stay longer.

(ii) There exists $t_{b}<T$, such that over the interval $\left[t_{b}, T\right], k(t)$ will be falling $(\dot{k}<0)$.

(iii) There exists $t_{a}>0$, such that over the interval $\left[0, t_{a}\right], k(t)$ will be falling $(\dot{k}<0)$.

The second best allocation scheme offered by the firm differs from the first best because, knowing that the worker has the freedom to quit at any time, it has to propose a contract in which the path of allocation of working time between tasks and the wage profile are suitably designed to counter the worker's incentives to leave the firm. The employer distorts the path of knowledge accumulation in order to reduce the total wage payment it has to give to retain the worker. It manipulates the evolution of her outside option, $V^{0}(t)=(T-t) s(K(t))$. Let us illustrate the intuition of this result with an example:

Example 2 [Second best allocation of time between tasks]: Let us specify the functions as follows. $\pi(K)=A K$ with $A>0, \hat{\pi}(K)=\beta A K$ with $\beta \in(0,1), I(K)=D K$ with $D \geq 0$ and $v(u)=u-\frac{1}{2} u^{2}$. Assuming that $k$ increases over only one interval $\left[t_{a}, t_{b}\right]$, the optimal path of knowledge accumulation and the optimal fraction of working time devoted to the knowledge task can be illustrated with the following graphs $(T=1, A=1, D=0, \beta=0.8) .{ }^{10}$

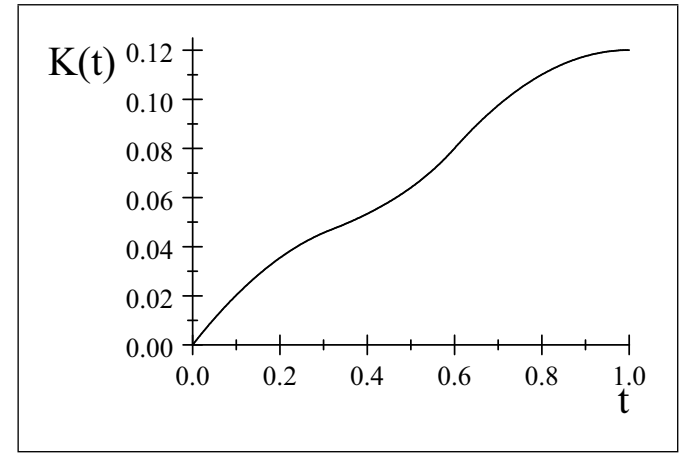

Cumulated knowledge

\footnotetext{
${ }^{10}$ The resolution of the firm's problem under this specification is relegated to the appendix.
} 


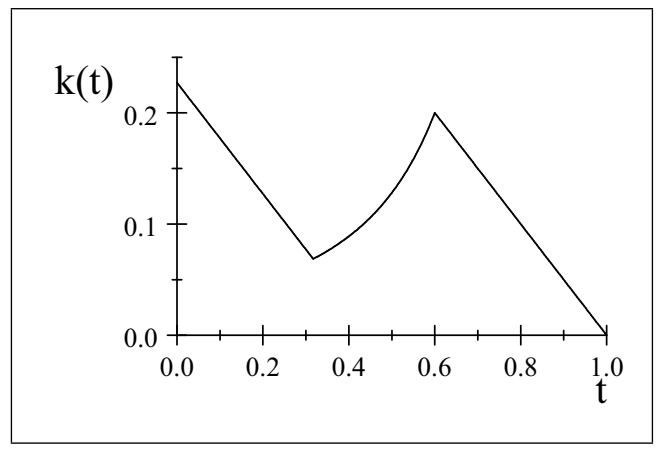

Knowledge task share of working time

The intuition behind Proposition 2 can be illustrated in this example. The outside option of the knowledge worker is given by:

$$
V^{0}(t)=(T-t) A \beta K(t)
$$

Now let us compare how the outside option evolves through time when the employer uses the first best working time splitting path and when he uses the second best path:

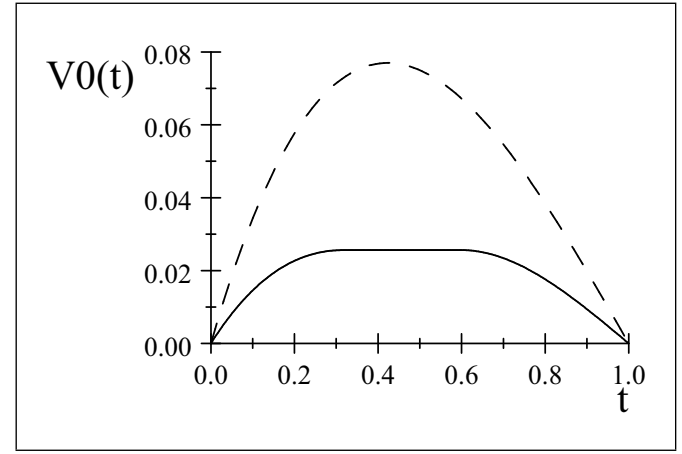

Knowledge worker's outside option

The dotted curve (respectively, the continuous curve) represents the outside option of the knowledge worker when the employer uses the first best (respectively, second best) allocation of working time. In the second best situation, the firm has to give a cumulated wage that fulfils condition (5). If it uses the first best path, it has to pay an amount $S_{T} \simeq 0.08$ to the worker at the end of the horizon. According to proposition 2, this is not optimal. If instead the firm uses the second best path, the outside option curve becomes flatter and it only has to pay around 0.025 to the knowledge worker.

In order to focus on the time allocation profile, we have made the simplifying assumption that the employer can defer payments of the salary mass $S_{T}$ (except for possibly some basic amount per period, say $\underline{w}$, which we have normalized to zero) until the end of the time horizon. This assumption can be easily relaxed. Notice that in the third panel of this 
example, the worker's outside option reaches a plateau and stays constant over an interval $\left[t_{a}, t_{b}\right]$. Over this interval, $Y^{*}(t)=S_{T}$, with $Y^{*}(t)=(T-t) s\left(K^{*}(t)\right)-\int_{t}^{T} I\left(K^{*}(\tau)\right) d \tau$ and $K^{*}(t)$ is the (second best) optimal path of cumulated knowledge. Afterwards, over the time interval $\left[t_{b}, T\right], Y^{*}(t)$ declines monotonely toward zero. This indicates that the salary mass $S_{T}$ can be paid in installments over the time interval $\left[t_{b}, T\right]$. What is required is that

$$
\int_{t_{b}}^{T} w(\tau) d \tau=S_{T} \text { and } \int_{t}^{T} w(\tau) d \tau \geq Y^{*}(t) \text { for all } t \in\left[t_{b}, T\right]
$$

Thus the firm can spread the payments of salary by setting, for example,

$$
\int_{t}^{T} w(\tau) d \tau=Y^{*}(t) \text { for all } t \in\left[t_{b}, T\right]
$$

Then, differentiating (9), we obtain

$$
w(t)=-\dot{Y}^{*}(t) \text { for all } t \in\left[t_{b}, T\right]
$$

and

$$
\dot{w}(t)=-\ddot{Y}^{*}(t) \text { for all } t \in\left[t_{b}, T\right] .
$$

The time path of wage over $\left[t_{b}, T\right]$ can thus be computed and plotted, using the above numerical example.

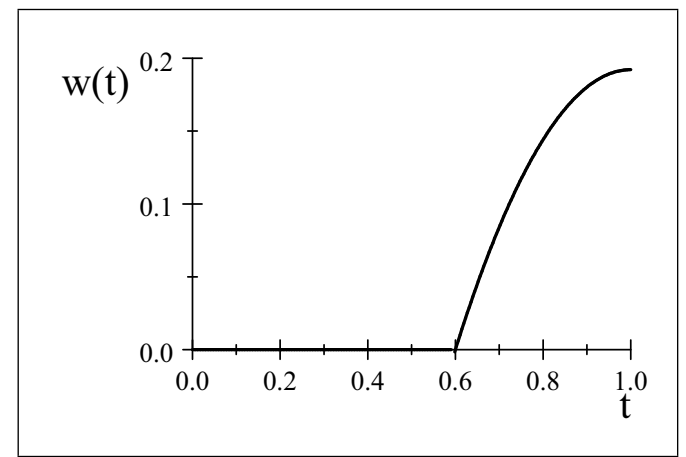

Knowledge worker's wage

The wage of the knowledge worker is at first constant and then increases up to the end of her career.

\section{$5 \quad$ Effect of the specificity of knowledge}

In this section we focus on the role of the specificity of knowledge on the second best contract scheme. Becker (1962) distinguishes two categories of human capital, specific and general 
human capital. Specific human capital is related to a specific firm's products or services whereas general human capital can be used in a large range of different firms. Along these lines, we now study the effect of the degree of specificity of knowledge ( $\beta=0$ being full specificity and $\beta=1$ being full general knowledge) on (a) the duration of the time period $\left[t_{a}, t_{b}\right]$ where time devoted to the knowledge task $k$ is increasing; ${ }^{11}$ (b) the amount of knowledge cumulated over the whole horizon $[0, T]$; and (c) the total wage of the knowledge worker, $S_{T}=\int_{0}^{T} w(\tau) d \tau$. We concentrate on the following specification of the general model: we assume, as in examples 1 and 2 that the profit generated by knowledge inside the firm is proportional to the accumulated amount of knowledge, $\pi(K)=A K$. The degree of knowledge specificity is denoted $\beta \in(0,1)$. The profit generated by knowledge outside the firm is then $\hat{\pi}(K)=\beta A K$. The value of the routine task is specified as $v(u)=u-\frac{1}{2} u^{2}$. Finally, for the sake of simplicity, we assume that there is no ego rent, i.e. $I(K)=0$. Using this specification, we can show the following result:

Proposition 3 [Specificity of knowledge]: As knowledge becomes more specific ( $\beta$ decreases):

(i) The phase of increasing fraction of time devoted to the knowledge task becomes shorter. Formally, $\left|t_{b}-t_{a}\right|$ decreases when $\beta$ decreases.

(ii) The total amount of knowledge accumulated over the whole horizon increases. Formally, $K(T)$ increases when $\beta$ decreases.

(iii) The change in the total wage of the knowledge worker is ambiguous. This is because while the total wage increases with $\beta$ for a given $K(T)$, the latter decreases with $\beta$.

The first two results (i) and (ii) are quite intuitive. When knowledge becomes more firm-specific, the value of the outside option of the knowledge worker becomes smaller and it becomes easier to retain her, i.e. the situation is then closer to the first best situation. Then the duration of the phase where $k$ increases becomes smaller. (Note that there is no such phase in the first best case, which is incentive compatible in the situation where $\beta=0$ ). The total amount of knowledge accumulated over the whole horizon also increases.

To understand the third point (iii), note that an increase in the specificity of knowledge has two effects on the outside option, which work in opposite directions. On the one hand, the more specific the knowledge, the lower the value of the outside option of the knowledge worker, and this allows the employer to offer her a lower total wage. On the other hand, when knowledge becomes more specific, the employer can afford to leave her more time to

\footnotetext{
${ }^{11} \mathrm{We}$ assume here that there is only one interval of time where $k$ increases.
} 
accumulate knowledge. Hence, the amount of accumulated knowledge is larger which in turn increases the knowledge worker's outside option. These two opposite effects explain the ambiguous effect of knowledge specificity on the worker's wage. As an illustrative example, Table 1 summarizes our numerical results for $A=1$ and $T=47$ :

\begin{tabular}{|l|l|l|l|l|}
\hline$\beta$ & $t_{a}$ & $t_{b}$ & $V_{f}$ & $S_{T}$ \\
\hline 0 & $/$ & $/$ & 34055 & 0 \\
\hline 0.2 & 19.32 & 21.23 & 23334 & 3422.3 \\
\hline 0.4 & 18.64 & 22.68 & 16181 & 5752.3 \\
\hline 0.6 & 17.79 & 24.22 & 10342 & 7095.5 \\
\hline 0.7 & 17.29 & 25.01 & 7856.6 & 7438.4 \\
\hline 0.8 & 16.72 & 25.86 & 5587.2 & 7555.5 \\
\hline 0.85 & 16.45 & 26.23 & 4628.9 & 7617.1 \\
\hline 0.9 & 16.15 & 26.64 & 3667.2 & 7595.8 \\
\hline 0.95 & 15.83 & 27.05 & 2751.9 & 7543.1 \\
\hline 1 & 15.40 & 27.60 & 1649.9 & 7210.3 \\
\hline
\end{tabular}

Table 1: numerical results

In this example, the total wage of the knowledge worker is indeed not monotonic with respect to the degree of specificity of knowledge. The total wage increases when knowledge is sufficiently specific, i.e. $\beta \in[0,0.85]$, and decreases when knowledge is sufficiently general $\beta \in[0.9,1]$.

\section{Concluding Remarks}

We have developed a simple model of task allocation for knowledge workers. We obtain the novel result that the time path of the fraction of working time allocated to a knowledge creation task is non-monotone. This fraction is highest at the early career stage, falls gradually, then rises again, before falling finally toward zero. This feature seems consistent with stylized facts in academic careers. The phenomenon is explained in terms of the employer's design of incentive contracts that motivate the knowledge worker not to quit. We introduced a variable $Y(t)$ that represents the worker's valuation of her outside opportunity (net of the present value of future non-wage benefits that she must forgo if she quits at time $t$ ). We showed that the employer manipulates the time path of this variable by prescribing a non-monotone path of work time allocation. There is at least one interval of time where the fraction of time allocated to the knowledge creation task increases. This is practically an appeal by the employer to the mid-carreer worker: "if you stay with me, your will accumulate knowledge at a faster rate than in the past." In this second best world, the 
worker's valuation of her outside opportunity reaches a plateau (rather than a peak, as in the joint-maximization scenario) and falls only in the last stage of her career.

For simplicity, we have assumed that the firm defers payments of the salary mass (except for possibly some basic amount per period) until the end of the time horizon. We have indicated that this can be relaxed, allowing the firm to spread the salary mass over a number of periods.

Our model has a number of limitations which are necessary to keep the analysis simple. For instance, we have assumed that the employer can make binding commitment. In a future extension, we would allow both sides to renegotiate at each point of time. This could result in a unique wage profile.

\section{Appendix A: Proofs}

Proof of Proposition 1: Since $\widehat{\pi}(K)<\pi(K)$, the value of knowledge is larger when the employee stays with the firm, the optimal quitting time is $t^{*}=T$. The joint surplus maximization problem reduces to

$$
\max _{k} \int_{0}^{T} e^{-r \tau}(I(K(\tau))+\pi(K(\tau))+v(1-k(\tau))) d \tau,
$$

where $0 \leq k(\tau) \leq 1$ and $\dot{K}(\tau)=k(\tau)$.

Let $\psi$ be the co-state variable, $\lambda$ and $\mu$ be the multipliers associated with the constraint $k \geq 0$ and $1-k \geq 0$. Write the Lagrangian

$$
L=I(K)+\pi(K)+v(1-k)+\psi k+\lambda k+\mu(1-k)
$$

The necessary conditions are

$$
\begin{gathered}
\frac{\partial L}{\partial k}=-v^{\prime}(1-k)+\psi+\lambda-\mu=0 \\
\lambda \geq 0, \quad k \geq 0, \quad 1 \geq k \quad \lambda k=0, \quad \mu(1-k)=0 \\
\dot{\psi}=r \psi-\frac{\partial L}{\partial K}=r \psi-I^{\prime}(K)-\pi^{\prime}(K)
\end{gathered}
$$

and the transversality condition is

$$
\psi(T)=0
$$

Then

$$
(\dot{\psi}(\tau)-r \psi(\tau)) e^{-r \tau}=-\left(I^{\prime}(K)+\pi^{\prime}(K)\right) e^{-r \tau}
$$


and integration gives

$$
\psi(T) e^{-r T}-\psi(t) e^{-r t}=-\int_{t}^{T}\left(I^{\prime}(K(\tau))+\pi^{\prime}(K(\tau))\right) e^{-r \tau} d \tau
$$

It follows that

$$
\psi(t)=e^{r t} \int_{t}^{T}\left(I^{\prime}(K(\tau))+\pi^{\prime}(K(\tau))\right) e^{-r \tau} d \tau>0 \text { for all } t<T
$$

Assuming an interior solution, we have $\mu(t)=\lambda(t)=0$. Using (17) and (11) and differentiating, we have

$$
-v^{\prime \prime}(1-k) \dot{k}=\dot{\psi}<0
$$

(Note: along the optimal path it must hold that $\dot{\psi}(t)<0$ because if $\dot{\psi}(t)$ were ever positive or zero at some $t$ then it would not be possible for $\psi$ to reach zero at $T$ )

\section{Proof of Proposition 2:}

The firm offers to the employee a package deal whereby it pays her a sum $S_{T}$ at time $T$, provided that she stays with the firm until time $T$, and works for the firm according to a prescribed time allocation scheme $(k(\tau), 1-k(\tau))$ where $k(\tau)$ is the fraction of the workday to be spent on the knowledge creation task, and $1-k(\tau)$ is the fraction of the day to be spent on other tasks. If the employee quits at any time $t<T$, she will forfeit the sum $S_{T}$, and present value her full income stream from time $t$ to $T$ will be

$$
V_{q}(t)=\int_{t}^{T} s(K(t)) d t=(T-t) s(K(t)) .
$$

If she stays with the firm, the present value of her full income stream from time $t$ to $T$ is

$$
V_{w}(t)=\int_{t}^{T} I(K(\tau)) d \tau+S_{T}
$$

The employee will stay with the firm until $T$ if and only if $V_{w}(t) \geq V_{q}(t)$ for all $t \in[0, T]$. Thus, the firm's package deal must satisfy the non-quitting constraint

$$
S_{T} \geq(T-t) s(K(t))-\int_{t}^{T} I(K(\tau)) d \tau \text { for all } t \in[0, T] .
$$

It is convenient to introduce the following state variable

$$
Y(t) \equiv(T-t) s(K(t))-\int_{t}^{T} I(K(\tau)) d \tau
$$

The variable $Y(t)$ represents the worker's valuation of her outside opportunity (net of the present value of future non-wage benefits that she must forgo if she quits at time $t$ ). Then, 
recalling that $\dot{K}(t)=k(t)$, we obtain the following differential equation for the state variable $Y(t)$ :

$$
\dot{Y}(t)=(T-t) s^{\prime}(K(t)) k(t)-s(K(t))+I(K(t)) \equiv g(t, k(t), K(t)), Y(T)=0,
$$

and the non-quitting constraint becomes

$$
S_{T}-Y(t) \geq 0 \text { for all } t \in[0, T] .
$$

The firm must now choose the time path of the control variable $k(t)$, and the terminal payment $S_{T}$ to maximize the objective function

$$
V_{f}=\int_{0}^{T}[\pi(K(t))+v(1-k(t))] d t-S_{T} \equiv \int_{0}^{T}[\pi(K(t))+v(1-k(t))] d t+G\left(S_{T}\right)
$$

subject to the differential equations for $K(t)$ and $Y(t)$, with boundary conditions $K(0)=$ $0, Y(T)=0, K(T)$ free, $Y(0)$ free, and the inequality constraints $S_{T}-Y(t) \geq 0,0 \leq k(t) \leq 1$.

Since the constraint $S_{T}-Y(t) \geq 0$ involves a constant $S_{T}$ which is to be chosen optimally (as $S_{T}$ also appears in the firm's objective function $V_{f}$ ), it is treated as a control parameter, and the necessary conditions can be derived using Hestenes's approach (see Long and Leonard, 1992, Chapter 7, Theorem 7.8.1, pp. 247-250, or Takayama (1985, pp 657-660).

\section{Necessary conditions}

Let $\psi(t)$ and $\rho(t)$ be the co-state variables associated with the state variables $K(t)$ and $Y(t)$ respectively. Let $\lambda(t), \mu(t)$ and $\varphi(t)$ be the multipliers associated with the inequality constrants $k(t) \geq 0,1-k(t) \geq 0$ and $S_{T}-Y(t) \geq 0$. Define

$$
g(K, k, t) \equiv(T-t) s^{\prime}(K) k-s(K)+I(K)
$$

Define the Hamiltonian $H$ and the Lagragian $L$ as follows

$$
\begin{gathered}
H=\pi(K)+v(1-k)+\psi k+\rho g(K, k, t) \\
L=H+\lambda k+\mu[1-k]+\varphi\left[S_{T}-Y\right]
\end{gathered}
$$

The necessary conditions include

$$
\begin{gathered}
\frac{\partial L}{\partial k}=-v^{\prime}(1-k)+\psi+\lambda-\mu=0 \\
\lambda \geq 0, k \geq 0, \lambda k=0, \mu \geq 0,1-k \geq 0, \mu(1-k)=0 \\
\varphi \geq 0, S_{T}-Y \geq 0, \varphi\left(S_{T}-Y\right)=0
\end{gathered}
$$




$$
\begin{gathered}
\dot{\psi}=-\frac{\partial L}{\partial K}=-\pi^{\prime}(K)-\rho \frac{\partial g}{\partial K} \\
\dot{\rho}=-\frac{\partial L}{\partial Y}=\varphi
\end{gathered}
$$

The following three transversality conditions are also necessary. Since $K_{T}$ and $Y_{0}$ are free,

$$
\begin{gathered}
\psi(T)=0 \\
\rho(0)=0
\end{gathered}
$$

and the choice of $S_{T}$ must be such that the following transversality with respect to $S_{T}$ is satisfied

$$
G^{\prime}\left(S_{T}\right)+\int_{0}^{T} \frac{\partial L}{\partial S_{T}} d t=0
$$

i.e.

$$
-1+\int_{0}^{T} \varphi(t) d t=0
$$

Since $\varphi(t) \geq 0$, equation (21) implies that there must exist at least a time interval $\left(t^{\prime}, t^{\prime \prime}\right)$ where $\varphi(t)$ is strictly positive. On each interval $\left(t^{\prime}, t^{\prime \prime}\right)$ where $\varphi(t)>0$, we have $S_{T}=Y$. Hence $\dot{Y}(t)=0$ and $\ddot{Y}(t)=0$ for all $t \in\left(t^{\prime}, t^{\prime \prime}\right)$. Specifically

$$
\ddot{Y}(t)=-s^{\prime} k-s^{\prime} k+(T-t) s^{\prime \prime} k^{2}+(T-t) s^{\prime} \dot{k}+I^{\prime} k=0, \text { for all } t \in\left(t^{\prime}, t^{\prime \prime}\right)
$$

Then,

$$
\begin{aligned}
\dot{k} & =\frac{\left(2 s^{\prime}-I^{\prime}\right) k-(T-t) s^{\prime \prime} k^{2}}{(T-t) \hat{\pi}^{\prime}} \\
& =\frac{\left(2 \hat{\pi}^{\prime}+I^{\prime}\right) k-(T-t) s^{\prime \prime} k^{2}}{(T-t) \hat{\pi}^{\prime}}>0 \text { for all } t \in\left(t^{\prime}, t^{\prime \prime}\right)
\end{aligned}
$$

There may be more than one interval where $\varphi(t)>0$. Let $t_{a}$ be such that $\varphi(t)=0$ for all $t \in\left[0, t_{a}\right]$ and $t_{b}$ be such that $\varphi(t)=0$ for all $t \in\left[t_{b}, T\right]$.

Over $\left[0, t_{a}\right]$, we have $\varphi(t)=0$ then $\dot{\rho}=0$. Since $\rho(0)=0$, we have $\rho(t)=0$ for all $t \in\left[0, t_{a}\right]$. Conditions (19) and (20) give

$$
v^{\prime}=\psi \text { and } \dot{\psi}=-\pi^{\prime} \text { for all } t \in\left[0, t_{a}\right]
$$

Differentiating the first equality above with respect to time, we obtain

$$
\dot{\psi}=-v^{\prime \prime} \dot{k}=-\pi^{\prime}<0 \text { for all }\left[0, t_{a}\right]
$$

which implies that $\dot{k}<0$. 
Over $\left[t_{b}, T\right]$, we have $\varphi(t)=0$ then $\dot{\rho}=0$. Hence $\rho(t)=\rho\left(t_{b}\right)=\int_{t_{a}}^{t_{b}} \varphi(s) d s=1$. Conditions (19) and (20) can be rewritten as follows:

$$
v^{\prime}-(T-t) s^{\prime}=\psi \text { for all } t \in\left[t_{b}, T\right]
$$

and,

$$
\begin{aligned}
\dot{\psi} & =-\pi^{\prime}-\left(-s^{\prime}+(T-t) s^{\prime \prime} k+I^{\prime}\right) \\
& =s^{\prime}-\pi^{\prime}-I^{\prime}-(T-t) s^{\prime \prime} k, \text { for all } t \in\left[t_{b}, T\right]
\end{aligned}
$$

Differentiating the first equality above with respect to time, we have:

$$
\dot{\psi}=-v^{\prime \prime} \dot{k}+s^{\prime}-(T-t) s^{\prime \prime} k=s^{\prime}-\pi^{\prime}-I^{\prime}-(T-t) s^{\prime \prime} k
$$

Then, we conclude

$$
\dot{k}=-\frac{\pi^{\prime}+I^{\prime}}{-v^{\prime \prime}}<0 \text { for all } t \in\left[t_{b}, T\right]
$$

If there are at least two intervals where $\varphi(t)>0$, there must exist an interval $\left(t_{1}, t_{2}\right)$ such that $\varphi(t)=0$ for all $t \in\left(t_{1}, t_{2}\right)$ and $\varphi\left(t_{1}-\varepsilon\right)>0$ and $\varphi\left(t_{2}+\varepsilon\right)>0$. Over $\left(t_{1}, t_{2}\right)$, we have $\dot{\rho}=0$ and

$$
0 \leq \rho(t)=\rho\left(t_{1}\right)=\int_{t_{a}}^{t_{1}} \varphi(\tau) d \tau<1 \text { for all } t \in\left(t_{1}, t_{2}\right)
$$

Condition (19) gives

$$
0=-v^{\prime}+\psi+\rho\left(t_{1}\right)\left\{(T-t) s^{\prime}\right\} \text { for all } t \in\left(t_{1}, t_{2}\right)
$$

Differentiating this equation with respect to time leads to:

$$
\dot{\psi}=-v^{\prime \prime} \dot{k}+\rho\left(t_{1}\right)\left\{s^{\prime}-(T-t) s^{\prime \prime} k\right\}, \text { for all } t \in\left(t_{1}, t_{2}\right)
$$

and using (20), we have:

$$
\begin{array}{r}
\dot{\psi}=-v^{\prime \prime} \dot{k}+\rho\left(t_{1}\right)\left\{s^{\prime}-(T-t) s^{\prime \prime} k\right\} \\
=-\pi^{\prime}-\rho\left(t_{1}\right)\left\{-s^{\prime}+(T-t) s^{\prime \prime} k+I^{\prime}\right\},
\end{array}
$$

or,

$$
\dot{k}=\frac{-\pi^{\prime}-\rho\left(t_{1}\right) I^{\prime}}{-v^{\prime \prime}}<0 \text { for all } t \in\left(t_{1}, t_{2}\right)
$$


Proof of Proposition 3: We use the results derived in example 2 with $D=0$. We first show point (i). Using (68) and combining (63) and (70), we obtain two conditions that characterize the interval $\left[t_{a}, t_{b}\right]$ :

$$
\begin{aligned}
\beta A & =-A \ln \left(\frac{T-t_{b}}{T-t_{a}}\right)+\frac{2}{3}\left(1-\left(\frac{T-t_{b}}{T-t_{a}}\right)^{3}\right) \\
\frac{\left(T-t_{b}\right)^{3}}{T-t_{a}} & =\frac{1}{2} \frac{\left(T-t_{a}\right)\left(t_{a}\right)^{2}}{\left(T-2 t_{a}\right)}
\end{aligned}
$$

Multiplying both sides of $(36)$ by $1 /\left(T-t_{a}\right)^{2}$, we have:

$$
\left(\frac{T-t_{b}}{T-t_{a}}\right)^{3}=\frac{1}{2} \frac{\left(t_{a}\right)^{2}}{\left(T-2 t_{a}\right)\left(T-t_{a}\right)}
$$

Plugging this condition into (35), we obtain:

$$
\beta A=-\frac{1}{3} A \ln \left(\frac{1}{2} \frac{\left(t_{a}\right)^{2}}{\left(T-2 t_{a}\right)\left(T-t_{a}\right)}\right)+\frac{2}{3}\left(1-\frac{1}{2} \frac{\left(t_{a}\right)^{2}}{\left(T-2 t_{a}\right)\left(T-t_{a}\right)}\right) .
$$

This condition characterizes $t_{a}$ as a function of $\beta$. Differentiating this condition with respect to $\beta$, we have:

$$
\frac{d t_{a}}{d \beta}=-\frac{3 A t_{a}\left(T-t_{a}\right)^{2}\left(T-2 t_{a}\right)^{2}}{\left(A\left(T-2 t_{a}\right)\left(T-t_{a}\right)+\left(t_{a}\right)^{2}\right)\left(2 T-3 t_{a}\right) T}<0 .
$$

The function $t_{a} \mapsto \frac{1}{2} \frac{\left(t_{a}\right)^{2}\left(T-t_{a}\right)^{2}}{\left(T-2 t_{a}\right)}$ increases with respect to $t_{a}$. Indeed, the derivative of the function $t_{a} \mapsto\left(t_{a}\right)^{2}\left(T-t_{a}\right)^{2}$ is given by $t_{a} \mapsto 4 t_{a}\left(T-t_{a}\right)\left(\frac{T}{2}-t_{a}\right)>0$. Using (36), we have that $t_{b}$ decreases when $t_{a}$ increases. Hence, $t_{b}$ increases with respect to $\beta$.

Now consider point (ii). Using (63), (64) and (72), the total amount of accumulated knowledge is given by:

$$
K(T)=2 A\left(T-t_{b}\right)^{2}
$$

Hence $K(T)$ decreases with respect to $\beta$.

Regarding point (iii), we have

$$
\begin{aligned}
S_{T} & =Y\left(t_{b}\right)=\left(T-t_{b}\right) \beta A K\left(t_{b}\right) \\
& =\beta A^{2}\left(T-t_{b}\right)^{3} \\
& =\frac{1}{\sqrt{2}} \beta A^{3 / 2}(K(T))^{3 / 2}
\end{aligned}
$$




\section{Material for the examples and a sufficiency theorem}

Computations for Example 1: Assuming an interior solution, the first order conditions for the first best programme become:

$$
\begin{gathered}
\psi=k, \\
\dot{\psi}=-(A+D),
\end{gathered}
$$

and,

$$
\psi(T)=0 .
$$

Integration of (38) leads to

$$
\psi(t)=(A+D)(T-t)
$$

and then, the first best working time splitting is such that

$$
k(t)=(A+D)(T-t) .
$$

\section{Computations for Example 2:}

Assuming an interior solution, the first order conditions for the second best programme become:

$$
\begin{gathered}
-k+\psi+\rho(T-t)(\beta A+D)=0, \\
\dot{\psi}=-(A+D)+\rho \beta A \\
\dot{\rho}=\varphi \\
\varphi(t) \geq 0, S_{T}-Y(t) \geq 0, \\
\varphi(t)\left[S_{T}-Y\right]=0 \\
\psi(T)=0 \\
\rho(0)=0 \\
\int_{0}^{T} \varphi(t) d t=1
\end{gathered}
$$

where,

$$
Y(t)=(T-t)(\beta A+D) K(t)-D \int_{t}^{T} K(\tau) d \tau
$$


Let us find the solution such that $k$ increases over only one interval $\left[t_{a}, t_{b}\right]$. Over this interval, we have $\dot{Y}(t)=0$, which can be written as:

$$
\frac{k(t)}{K(t)}=\frac{\beta A}{\beta A+D} \frac{1}{T-t} \text { for all } t \in\left[t_{a}, t_{b}\right]
$$

Integrating this equation over $\left[t_{a}, t\right]$, we obtain:

$$
\ln \frac{K(t)}{K\left(t_{a}\right)}=\frac{\beta A}{\beta A+D} \ln \frac{T-t_{a}}{T-t}
$$

and then for all $t \in\left[t_{a}, t_{b}\right]$,

$$
K(t)=K\left(t_{a}\right)\left(\frac{T-t_{a}}{T-t}\right)^{\frac{\beta A}{\beta A+D}} .
$$

Using (23) we have, over $\left[t_{a}, t_{b}\right]$ :

$$
\begin{aligned}
\dot{k} & =\frac{\left(2 \hat{\pi}^{\prime}+I^{\prime}\right) k-(T-t) s^{\prime \prime} k^{2}}{(T-t) \hat{\pi}^{\prime}} \\
& =\frac{(2 \beta A+D) k}{(T-t) \beta A} .
\end{aligned}
$$

Integrating over $\left[t_{a}, t\right]$ and rearranging, we have

$$
k(t)=k\left(t_{a}\right)\left(\frac{T-t_{a}}{T-t}\right)^{\frac{2 \beta A+D}{\beta A}}
$$

Now by differentiating (49) we obtain, for all $t \in\left[t_{a}, t_{b}\right]$ :

$$
k(t)=K\left(t_{a}\right) \frac{\beta A}{\beta A+D} \frac{\left(T-t_{a}\right)^{\frac{\beta A}{\beta A+D}}}{(T-t)^{\frac{2 \beta A+D}{\beta A}}} .
$$

Combining (51) and (52) we have

$$
k\left(t_{a}\right)=\frac{\beta A}{\beta A+D} \frac{K\left(t_{a}\right)}{T-t_{a}}
$$

Over $\left[0, t_{a}\right]$ we have $\varphi(t)=0$. Using (46), (42), (40) and (41), we obtain

$$
\psi=k \text { and } \dot{\psi}=-(A+D)
$$

Integrating $\dot{\psi}$ over $\left[t, t_{a}\right]$, we have, for all $t \in\left[0, t_{a}\right]$ :

$$
k(t)=k\left(t_{a}\right)-(A+D)\left(t-t_{a}\right) .
$$


Integrating this equation over $[0, t]$, we have, for all $t \in\left[0, t_{a}\right]$ :

$$
\begin{aligned}
K(t) & =k\left(t_{a}\right) t-(A+D) \frac{t^{2}}{2}+(A+D) t_{a} t \\
& =\left(\frac{\beta A}{\beta A+D} \frac{K\left(t_{a}\right)}{T-t_{a}}+(A+D) t_{a}-(A+D) \frac{t}{2}\right) t
\end{aligned}
$$

Over $\left[t_{b}, T\right]$ we have $\varphi(t)=0$ and $\rho(t)=1$. Conditions (40) and (41) become:

$$
-k+\psi+(T-t)(\beta A+D)=0
$$

and,

$$
\dot{\psi}=-(A+D)+\beta A .
$$

Integrating $\dot{\psi}$ over $[t, T]$, we have, for all $t \in\left[t_{b}, T\right]$ :

$$
\psi(T)-\psi(t)=-((1-\beta) A+D)(T-t)
$$

Using (45), this simplifies to

$$
\psi(t)=((1-\beta) A+D)(T-t)
$$

Plugging this condition into (56), we have

$$
k=(A+2 D)(T-t) .
$$

Integrating this equation over $\left[t_{b}, t\right]$, we get

$$
K(t)=K\left(t_{b}\right)+(A+2 D)\left(\left(t-t_{b}\right) T-\frac{1}{2} t^{2}+\frac{1}{2} t_{b}^{2}\right) .
$$

Finally, the cumulative time spend in the knowledge task is given by:

$$
K(t)=\left\{\begin{array}{c}
\left(\frac{\beta A}{\beta A+D} \frac{K\left(t_{a}\right)}{T-t_{a}}+(A+D) t_{a}-(A+D) \frac{t}{2}\right) t \text { if } t \in\left[0, t_{a}\right] \\
K\left(t_{a}\right)\left(\frac{T-t_{a}}{T-t}\right)^{\frac{\beta A}{\beta A+D}} \text { if } t \in\left[t_{a}, t_{b}\right] \\
K\left(t_{b}\right)+(A+2 D)\left(\left(t-t_{b}\right) T-\frac{1}{2} t^{2}+\frac{1}{2} t_{b}^{2}\right) \text { if } t \in\left[t_{b}, T\right]
\end{array}\right.
$$

We have:

$$
K\left(t_{a}\right)=\left(\frac{\beta A}{\beta A+D} \frac{K\left(t_{a}\right)}{T-t_{a}}+\frac{1}{2}(A+D) t_{a}\right) t_{a}
$$

or,

$$
K\left(t_{a}\right)=\frac{1}{2} \frac{(A+D)\left(t_{a}\right)^{2}}{1-\frac{\beta A}{\beta A+D} \frac{t_{a}}{T-t_{a}}}
$$


We have also:

$$
K\left(t_{b}\right)=K\left(t_{a}\right)\left(\frac{T-t_{a}}{T-t_{b}}\right)^{\frac{\beta A}{\beta A+D}}
$$

Differentiating (40) and plugging (41), we have

$$
(T-t)(\beta A+D) \dot{\rho}-\rho D=A+D+\dot{k} .
$$

Over $\left[t_{a}, t_{b}\right]$, using $\rho\left(t_{a}\right)=0$, the solution of this differential equation is such that

$$
\rho(t)=\left\{\begin{array}{c}
\frac{1}{D}\left\{\left(A+D+\dot{k}\left(t_{a}\right)\right)\left(\frac{T-t_{a}}{T-t}\right)^{\frac{D}{\beta A+D}}-(A+D+\dot{k}(t))\right\} \text { if } D>0 \\
\frac{1}{\beta A} \int_{t_{a}}^{t} \frac{A+\dot{k}(\tau)}{T-\tau} d \tau \text { if } D=0 \text { and } \beta A>0
\end{array}\right.
$$

Differentiating (51), we have

$$
\dot{k}(t)=k\left(t_{a}\right) \frac{2 \beta A+D}{\beta A} \frac{\left(T-t_{a}\right)^{2+\frac{D}{\beta A}}}{(T-t)^{3+\frac{D}{\beta A}}} .
$$

Plugging this expression into (66), and taking $t=t_{b}$ we obtain (notice that $\rho\left(t_{b}\right)=1$ ):

If $D>0$,

$$
\begin{aligned}
D= & \left(A+D+\frac{K\left(t_{a}\right)}{\left(T-t_{a}\right)^{2}}\left(\frac{2 \beta A+D}{\beta A+D}\right)\right)\left(\frac{T-t_{a}}{T-t_{b}}\right)^{\frac{D}{\beta A+D}} \\
& -(A+D)-\frac{K\left(t_{a}\right)}{\left(T-t_{a}\right)^{2}}\left(\frac{2 \beta A+D}{\beta A+D}\right)\left(\frac{T-t_{a}}{T-t_{b}}\right)^{3+\frac{D}{\beta A}},
\end{aligned}
$$

and, if $D=0$ and $\beta A>0$,

$$
\beta A=-A \ln \left(\frac{T-t_{b}}{T-t_{a}}\right)+\frac{2}{3} K\left(t_{a}\right)\left(T-t_{a}\right)\left(\frac{1}{\left(T-t_{b}\right)^{3}}-\frac{1}{\left(T-t_{a}\right)^{3}}\right)
$$

Now using (52) and (60) at $t=t_{b}$, we have

$$
k\left(t_{b}\right)=(A+2 D)\left(T-t_{b}\right)=K\left(t_{a}\right) \frac{\beta A}{\beta A+D} \frac{\left(T-t_{a}\right)^{\frac{\beta A}{\beta A+D}}}{\left(T-t_{b}\right)^{\frac{2 \beta A+D}{\beta A}}} .
$$

or,

$$
K\left(t_{a}\right)=(A+2 D) \frac{\beta A+D}{\beta A} \frac{\left(T-t_{b}\right)^{3+\frac{D}{\beta A}}}{\left(T-t_{a}\right)^{\frac{\beta A}{\beta A+D}}}
$$

Now we can find $t_{a}, t_{b}, K\left(t_{a}\right)$ and $K\left(t_{b}\right)$ by solving (63), (64), ((67) or (68)) and (70). And the optimal path is characterized by 


$$
k(t)=\left\{\begin{array}{c}
\frac{\beta A}{\beta A+D} \frac{K\left(t_{a}\right)}{T-t_{a}}+(A+D) t_{a}-(A+D) t \text { for } t \in\left[0, t_{a}\right], \\
K\left(t_{a}\right) \frac{\beta A}{\beta A+D}\left(T-t_{a}\right)^{\frac{\beta A}{\beta A+D}}(T-t)^{-\frac{2 \beta A+D}{\beta A+D}} \text { for } t \in\left[t_{a}, t_{b}\right], \\
(A+2 D)(T-t) \text { for } t \in\left[t_{b}, T\right]
\end{array}\right.
$$

or,

$$
K(t)=\left\{\begin{array}{c}
\left(\frac{\beta A}{\beta A+D} \frac{K\left(t_{a}\right)}{T-t_{a}}+(A+D) t_{a}-(A+D) \frac{t}{2}\right) t \text { if } t \in\left[0, t_{a}\right] \\
K\left(t_{a}\right)\left(\frac{T-t_{a}}{T-t}\right)^{\frac{\beta A}{\beta A+D}} \text { if } t \in\left[t_{a}, t_{b}\right] \\
K\left(t_{b}\right)+(A+2 D)\left(\left(t-t_{b}\right) T-\frac{1}{2} t^{2}+\frac{1}{2} t_{b}^{2}\right) \text { if } t \in\left[t_{b}, T\right]
\end{array}\right.
$$

\section{A sufficiency theorem}

Sufficiency theorem Let $\left(K^{*}, Y^{*}, k^{*}, S_{T}^{*}\right)$ be a candidate optimal solution. Assume that all the necessary conditions are satisfied by $\left(K^{*}, Y^{*}, k^{*}, S_{T}^{*}\right)$ and the associated time path $\left(\psi^{*}, \rho^{*}, \lambda^{*}, \mu^{*}, \varphi^{*}\right)$. Consider any alternative feasible plan $\left(K^{\#}, Y^{\#}, k^{\#}, S_{T}^{\#}\right)$. Let

$$
\begin{aligned}
L\left(K, Y, k, S_{T}, \psi^{*}, \rho^{*}, \lambda^{*}, \mu^{*}, \varphi^{*}, t\right) \equiv & \pi(K)+v(1-k)+\psi^{*} k+\rho^{*} g(K, k, t)+ \\
& \lambda^{*} k+\mu^{*}[1-k]+\varphi^{*}\left[S_{T}-Y\right]
\end{aligned}
$$

Let $V_{f}^{*}$ and $V_{f}^{\#}$ be the payoffs obtained by carrying the plans $\left(K^{*}, Y^{*}, k^{*}, S_{T}^{*}\right)$ and $\left(K^{\#}, Y^{\#}, k^{\#}, S_{T}^{\#}\right)$ respectively. Assume that $L$ is concave in $\left(K, Y, k, S_{T}\right)$. Then $V_{f}^{*} \geq V_{f}^{\#}$.

\section{Proof:}

For simplicity, we use the following notations

$$
L^{*}=L\left(K^{*}, Y^{*}, k^{*}, S_{T}^{*}, \psi^{*}, \rho^{*}, \lambda^{*}, \mu^{*}, \varphi^{*}, t\right)
$$

and

$$
L^{\#}=L\left(K^{\#}, Y^{\#}, k^{\#}, S_{T}^{\#}, \psi^{*}, \rho^{*}, \lambda^{*}, \mu^{*}, \varphi^{*}, t\right)
$$

where the asterisk over the multipliers indicates that we use the same path $\left(\psi^{*}, \rho^{*}, \lambda^{*}, \mu^{*}, \varphi^{*}\right)$ for both $L^{*}$ and $L^{\#}$.

Since $\lambda^{*} k^{*}=0, \mu^{*}\left[1-k^{*}\right]=0$ and $\varphi^{*}\left[S_{T}^{*}-Y^{*}\right]=0$,

$$
V_{f}^{*}=-S_{T}^{*}+\int_{0}^{T}\left[L^{*}-\psi^{*} k^{*}-\rho^{*} g\left(K^{*}, k^{*}, t\right)\right] d t
$$

Now,

$$
V_{f}^{\#}=-S^{\#}+\int_{0}^{T}\left[L^{\#}-\psi^{*} k^{\#}-\lambda^{*} g\left(K^{\#}, k^{\#}, t\right)-\lambda^{*} k^{\#}-\mu^{*}\left[1-k^{\#}\right]-\varphi^{*}\left[S_{T}^{\#}-Y^{\#}\right]\right] d t
$$


And, since $\lambda^{*} \geq 0, \mu^{*} \geq 0$ and $\varphi^{*} \geq 0$, and since feasibility requires that $k^{\#} \geq 0,1-k^{\#} \geq 0$ and $S_{T}^{\#}-Y^{\#}$

$$
V_{f}^{\#} \leq-S_{T}^{\#}+\int_{0}^{T}\left[L^{\#}-\psi^{*} k^{\#}-\lambda^{*} g\left(K^{\#}, k^{\#}, t\right)\right] d t
$$

Then

$$
\begin{aligned}
V_{f}^{*}-V_{f}^{\#} \geq & -\left(S_{T}^{*}-S_{T}^{\#}\right)-\int_{0}^{T}\left[\psi^{*} k^{*}-\psi^{*} k^{\#}\right] d t-\int_{0}^{T}\left[\rho^{*} g\left(K^{*}, k^{*}, t\right)-\rho^{*} g\left(K^{\#}, k^{\#}, t\right)\right] d t \\
& +\int_{0}^{T}\left[L\left(K^{*}, Y^{*}, k^{*}, S_{T}^{*}, \psi^{*}, \rho^{*}, \lambda^{*}, \mu^{*}, \varphi^{*}, t\right)-L\left(K^{\#}, Y^{\#}, k^{\#}, S_{T}^{\#}, \psi^{*}, \rho^{*}, \lambda^{*}, \mu^{*}, \varphi^{*}, t\right)\right] d t
\end{aligned}
$$

Now, under the assumption that $L\left(K, Y, k, S_{T}, \psi^{*}, \rho^{*}, \lambda^{*}, \mu^{*}, \varphi^{*}, t\right)$ is concave in $\left(K, Y, k, S_{T}\right)$,

$$
\begin{aligned}
& L^{*}-L^{\#} \equiv L\left(K^{*}, Y^{*}, k^{*}, S_{T}^{*}, \psi^{*}, \rho^{*}, \lambda^{*}, \mu^{*}, \varphi^{*}, t\right)-L\left(K^{\#}, Y^{\#}, k^{\#}, S_{T}^{\#}, \psi^{*}, \rho^{*}, \lambda^{*}, \mu^{*}, \varphi^{*}, t\right) \geq \\
& \left(k^{*}-k^{\#}\right) \frac{\partial L\left(K^{*}, Y^{*}, k^{*}, S_{T}^{*}, \psi^{*}, \rho^{*}, \lambda^{*}, \mu^{*}, \varphi^{*}, t\right)}{\partial k^{*}}+\left(K^{*}-K^{\#}\right) \frac{\partial L\left(K^{*}, Y^{*}, k^{*}, S_{T}^{*}, \psi^{*}, \rho^{*}, \lambda^{*}, \mu^{*}, \varphi^{*}, t\right)}{\partial K^{*}}+ \\
& \left(Y^{*}-Y^{\#}\right) \frac{\partial L\left(K^{*}, Y^{*}, k^{*}, S_{T}^{*}, \psi^{*}, \rho^{*}, \lambda^{*}, \mu^{*}, \varphi^{*}, t\right)}{\partial Y^{*}}+\left(S_{T}^{*}-S_{T}^{\#}\right) \frac{\partial L\left(K^{*}, Y^{*}, k^{*}, S_{T}^{*}, \psi^{*}, \rho^{*}, \lambda^{*}, \mu^{*}, \varphi^{*}, t\right)}{\partial S_{T}^{*}}
\end{aligned}
$$

Now, $\frac{\partial L^{*}}{\partial S_{T}^{*}}=\varphi^{*}$, and from the necessary conditions $\frac{\partial L^{*}}{\partial k^{*}}=0, \frac{\partial L^{*}}{\partial K^{*}}=-\dot{\psi}^{*}$ and $\frac{\partial L^{*}}{\partial Y^{*}}=-\dot{\rho}^{*}$ Then

$$
L^{*}-L^{\#} \geq-\dot{\psi}^{*}\left(K^{*}-K\right)-\dot{\rho}^{*}\left(Y^{*}-Y\right)+\left(S_{T}^{*}-S_{T}^{\#}\right) \varphi^{*}
$$

Therefore

$$
\begin{gathered}
V_{P}^{*}-V_{P} \geq-\left(S_{T}^{*}-S_{T}^{\#}\right)-\int_{0}^{T}\left[\dot{\psi}^{*}\left(K^{*}-K^{\#}\right)+\psi^{*} k^{*}-\psi^{*} k^{\#}\right] d t+ \\
\left(S_{T}^{*}-S_{T}^{\#}\right) \int_{0}^{T} \varphi^{*}(t) d t-\int_{0}^{T}\left[\dot{\rho}^{*}\left(Y^{*}-Y^{\#}\right)\right] d t+\int_{0}^{T}\left[\rho^{*} g\left(K^{*}, k^{*}, t\right)-\rho^{*} g\left(K^{\#}, k^{\#}, t\right)\right] d t
\end{gathered}
$$

Since $\int_{0}^{T} \varphi^{*}(t) d t=1$ by the transversality condition with respect to $S_{T}$, we end up with

$$
\begin{aligned}
V_{f}^{*}-V_{f}^{\#} \geq & \left.-\int_{0}^{T}\left[\dot{\psi}^{*} K^{*}+\psi^{*} \dot{K}^{*}\right] d t+\int_{0}^{T}\left[\dot{\psi}^{*} K^{\#}+\psi^{*} \dot{K}^{\#}\right] d t-\int_{0}^{T}\left[\dot{\rho}^{*} Y^{*}+\rho^{*} \dot{Y}^{*}\right)\right] d t+ \\
& \left.\int_{0}^{T}\left[\dot{\rho}^{*} Y^{\#}+\rho^{*} \dot{Y}^{\#}\right)\right] d t
\end{aligned}
$$

So,

$$
V_{f}^{*}-V_{f}^{\#} \geq-\int_{0}^{T} \frac{d}{d t}\left[\psi^{*} K^{*}\right] d t+\int_{0}^{T} \frac{d}{d t}\left[\psi^{*} K^{\#}\right] d t-\int_{0}^{T} \frac{d}{d t}\left[\rho^{*} Y^{*}\right] d t+\int_{0}^{T} \frac{d}{d t}\left[\rho^{*} Y^{\#}\right] d t
$$


The right-hand side equals

$$
\begin{aligned}
= & \psi^{*}(0) K^{*}(0)-\psi^{*}(T) K^{*}(T)-\psi^{*}(0) K^{\#}(0)+\psi^{*}(T) K^{\#}(T)+ \\
& \rho^{*}(0) Y^{*}(0)-\rho^{*}(T) Y^{*}(T)-\rho^{*}(0) Y^{\#}(0)+\rho^{*}(T) Y^{\#}(T)
\end{aligned}
$$

which is identically zero, because (i) $K^{*}(0)=K^{\#}(0)=0$ and $Y^{*}(T)=Y^{\#}(T)=0$ by feasibility, and (ii) $\psi^{*}(T)=0$ and $\rho^{*}(0)=0$ as transversality conditions for $K_{T}$ and $Y_{0}$ being free.

It follows that $V_{f}^{*}-V_{f}^{\#} \geq 0$.

\section{References}

[1] Acemoglu, D. and R. Shimer (1999). "Holdups and Efficiency with Search Frictions", International Economic Review, 40(4), pp. 827-49.

[2] Aghion, P., and Bolton, P. (1992). "An Incomplete Contracting Approach to Financial Contracting", Review of Economic Studies, 59, pp. 473-493.

[3] Aghion, P., and Tirole, J. (1997). "Formal and Real Authority in Organizations", Journal of Political Economy, 105, pp. 1-29.

[4] Baker, G., Gibbons, R., and Murphy, K.J. (2001). "Bringing the Market Inside the Firm?", American Economic Review, 91(2), pp. 212-218.

[5] Becker, G.S. (1962). "Investment in human capital: a theoretical analysis", Journal of Political Economy, 70, pp. 9-49.

[6] Becker, G.S. (1964 ). Human capital, New York: Columbia Univ. Press (for the NBER).

[7] Ben-Porath, Y. (1967). "The Production of Human Capital and the Life Cycle of Earnings", Journal of Political Economy, 75(4), pp. 352-365.

[8] Che, Y.-K., and Gale I. (2003). "Optimal Design of Research Contests", American Economic Review, 93, pp. 646-671.

[9] Che, Y.-K., and J. Sákovics, 2004. "A Dynamic Theory of Holdup", Econometrica, 72(4), pp. 1063-1103.

[10] Chung, T.-Y. (1991). "Incomplete Contracts, Specific Investments, and Risk Sharing", Review of Economic Studies, 58, pp. 1031-1042. 
[11] Compte, Olivier and Philippe Jehiel, (2003). "Gradualism in Bargaining and Contribution Games", C.E.R.A.S. Mimeo.

[12] Dewatripont, M., and Tirole, J. (1994). "Theory of Debt and Equity: Diversity of Securities and Manager-Shareholder Congruence", Quarterly Journal of Economics, 109, pp. 1027-1054.

[13] Dewatripont, M., P. Legros and S. A. Matthews (2003). "Moral Hazard and Capital Structure Dynamics", Journal of the European Economic Association, 1(4), pp. 890930.

[14] Drucker, P. F. (1995). "Managing in a Time of Great Change. New York: Truman Talley Books/Dutton.

[15] Edlin, A.S., and Reichelstein, S. (1996). "Holdups, Standard Breach Remedies, and Optimal Investment", American Economic Review, 86, pp. 478-501.

[16] Eldredge, N. and S. J. Gould (1972). "Punctuated Equilibria: An Alternative to Phyletic Gradualism", in T. J. M (Eds.): Models in Paleobiology, Scopf, pp. 82-115.

[17] Felli, L., and K. Roberts (2001). "Does Competition Solve the Hold-up Problem?", STICERD Theoretical Economics discussion paper No. TE/01/414, London School of Economics.

[18] Grossman, S., and Hart, O. (1986). "The Costs and Benefits of Ownership: A Theory of Lateral and Vertical Integration", Journal of Political Economy, 94, pp. 691-719.

[19] Guriev, S. and D. Kvasov (2005). "Contracting on Time", American Economic Review, pp. 1369-86.

[20] Hart, O.D., and Moore, J.D. (1990). "Property Rights and the Nature of the Firm", Journal of Political Economy, 98, 1119-1158.

[21] Hashimoto, M.(1981). "Firm-Specific Human Capital as Shared Investment", American Economic Review 71: 475-82.

[22] Holland, J. (1975). "Adaptation in Natural and Artificial Systems", Ann Arbor, MI: University of Michigan Press.

[23] Hvide, H. K and Kristiansen, E. G., (2007). "Management of Knowledge Workers", CEPR Discussion Papers 6039, C.E.P.R. Discussion Papers. 
[24] Klein, Benjamin, Robert G. Crawford, and Armen A. Alchian (1978). "Vertical Integration, Appropriable Rents, and the Competitive Contracting Process", Journal of Law and Economics, 21, pp. 297-326.

[25] Leonard, D. and N. V. Long (1992). Optimal Control Theory and Static Optimization in Economics, Cambridge University Press, Cambridge and New York.

[26] MacLeod, W. B. and J. M. Malcomson (1993). "Investments, Holdup, and the Form of Market Contract", American Economic Review, 28(2), pp. 811-37.

[27] March, J. (1991). "Exploration and Exploitation in Organisational Learning", Organisation Science, 2(1), pp. 71-87.

[28] Mincer, J. (1958). "Investment in Human Capital and Personal Income Distribution", Journal of Political Economy, 66(4), pp. 281-302.

[29] Mincer, J. (1962). "On-the-Job Training: Costs, Returns, and Some Implications", Journal of Political Economy, 70(5), pp. 50-79.

[30] Pitchford , R. and C. Snyder (2004). "A Solution to the Hold-up Problem involving Gradual Investment", Journal of Economic Theory, 114, pp. 88-103.

[31] Schumpeter, J. (1934). "The Theory of Economic Development", Cambridge. MA: Harvard University Press.

[32] Smid, B. and B. Volkerink (1999). "Investment in Firm-Specific and General Human Capital", 1999 EALE conference, Regensburg, Germany.

[33] Smirnov, V. and A. Wait (2004). "Timing of Investments, Holdup and Total Welfare", International Journal of Industrial Organization, 22(3), pp. 413-425.

[34] Prince, W. W. (2011). "Knowledge workers", in Encyclopedia of Business, 2nd ed.

[35] Takayama, A. (1986), Mathematical Economics, second edition, Cambridge University Press, Cambridge and New York.

[36] Williamson, O. E. (1979). "Transaction Cost Economics: The Governance of Contractual Relations", Journal of Law and Economics vol. 22: pp. 233-261. 


\section{Documents de Recherche parus en $2012^{1}$}

DR n²012 - 01 : Abdoul Salam DIALLO, Véronique MEURIOT, Michel TERRAZA «Analyse d'une nouvelle émergence de l'instabilité des prix des matières premières agricoles »

DR n²012 - 02 : Emmanuel DUGUET, Christine Le CLAINCHE «Chronic Illnesses and Injuries: An Evaluation of their Impact on Occupation and Revenues »

DR n²012 - 03 : Ngo Van LONG, Antoine SOUBEYRAN, Raphael SOUBEYRAN

« Knowledge Accumulation within an Organization »

\footnotetext{
${ }^{1}$ La liste intégrale des Documents de Travail du LAMETA parus depuis 1997 est disponible sur le site internet : http://www.lameta.univ-montp1.fr
} 
Contact :

Stéphane MUSSARD : mussard@lameta.univ-montp1.fr 


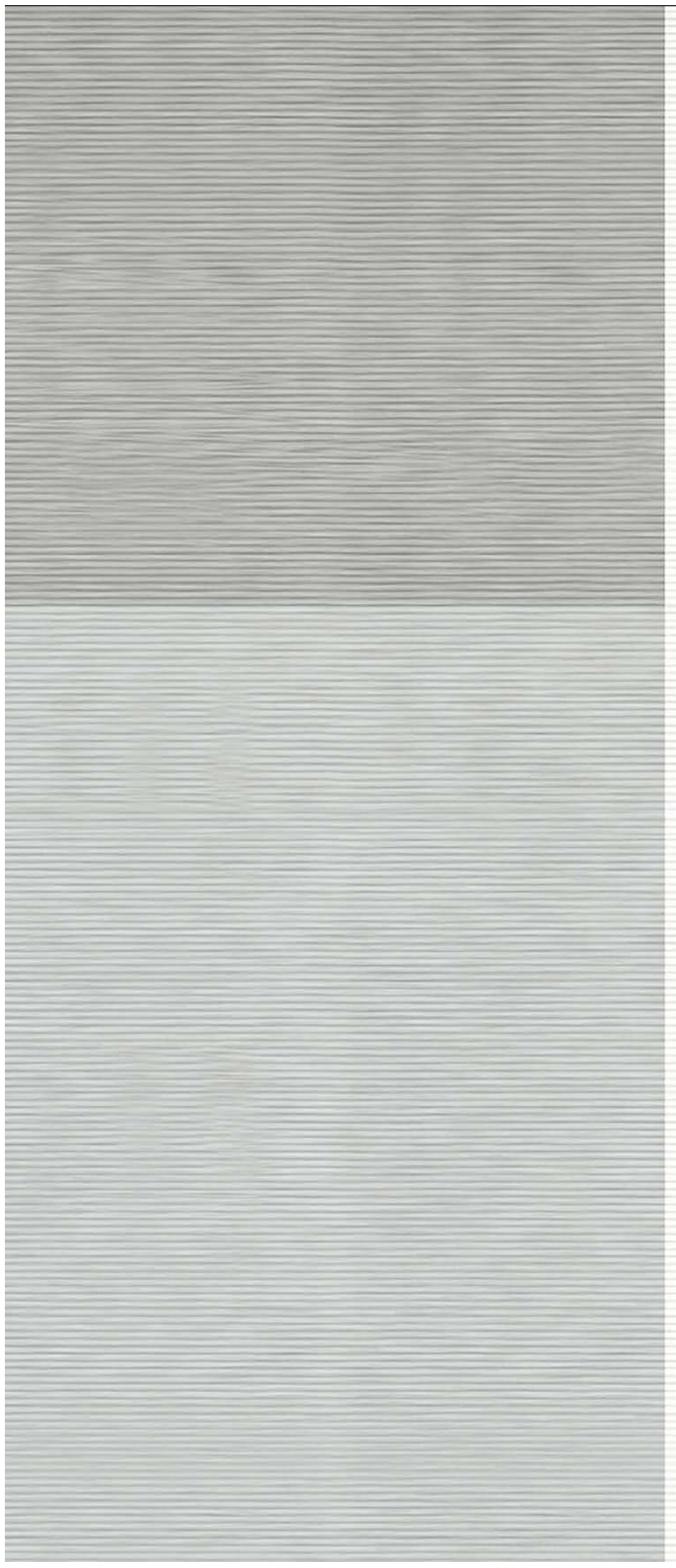

